\title{
Compositional analysis of Hassawi rice (Oryza sativa L.) and its associated glycaemic and insulinaemic indices
}

\author{
M. Q. Al-Mssallem ${ }^{1}$, G. S. Frost ${ }^{2}$ and J. E. Brown ${ }^{1}$ \\ ${ }^{1}$ Division of Nutritional Sciences, Faculty of Health and Medical Sciences, University of Surrey, Guildford GU2 7XH, UK \\ and ${ }^{2}$ Department of Investigative Medicine, Division of Integrative Science, Imperial College of Science Technology \\ and Medicine, University of London, London, UK
}

Rice is an important carbohydrate-rich staple food. A wide range of varieties exist globally mainly as a result of the conditions in which this staple food is grown. The type of dietary carbohydrate consumed has important health effects, in part because of their different impacts on blood glucose and insulin levels ${ }^{(1)}$. The present study examined a variety of rice consumed traditionally in Saudi Arabia (Hassawi rice) in terms of the macronutrient composition, enzymic glucose release in vitro ${ }^{(2)}$ and glycaemic and insulinaemic response in vivo.

For the in vivo study thirteen healthy participants were recruited from the postgraduate student and staff population at the University of Surrey. Each subject was randomly assigned to one of seven study legs according to the WHO protocol for glycaemic index testing ${ }^{(3)}$.

Compositional analysis ${ }^{(4)}$ highlighted that Hassawi rice contained (/100 g as eaten): $24 \mathrm{~g}$ carbohydrate, $4 \mathrm{~g}$ protein, $0.77 \mathrm{~g}$ fat and $0.5 \mathrm{~g}$ ash. In vitro carbohydrate hydrolysis revealed that the values of rapidly-available glucose (glucose released at $20 \mathrm{~min}$; RAG) and slowlyavailable glucose (glucose released at $120 \mathrm{~min}$; SAG) were 16 and $6 \mathrm{~g} / 100 \mathrm{~g}$ respectively. Glycaemic and insulinaemic indices were determined and were found to be 59 (SE 5) and 56 (SE 10) for Hassawi rice and 54 (SE 7) and 78 (SE 17) for Uncle Ben's rice (EU origin; Mars Inc., Brussels, Belgium) respectively. Results when compared with Uncle Ben's rice show that Hassawi rice is higher in protein, but lower in terms of both RAG and SAG, although the GI was comparable with that of Uncle Ben's rice.

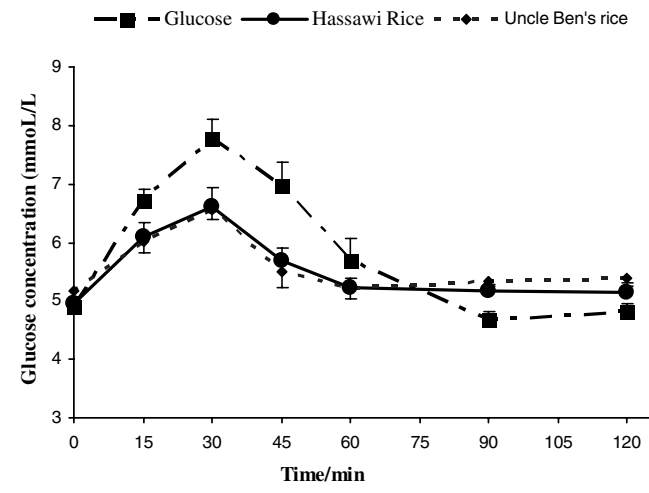

Fig. 1. Plasma glucose response during $2 \mathrm{~h}$ following reference glucose, Hassawi rice and Uncle Ben's rice. Values are means with their standard errors represented by vertical bars.

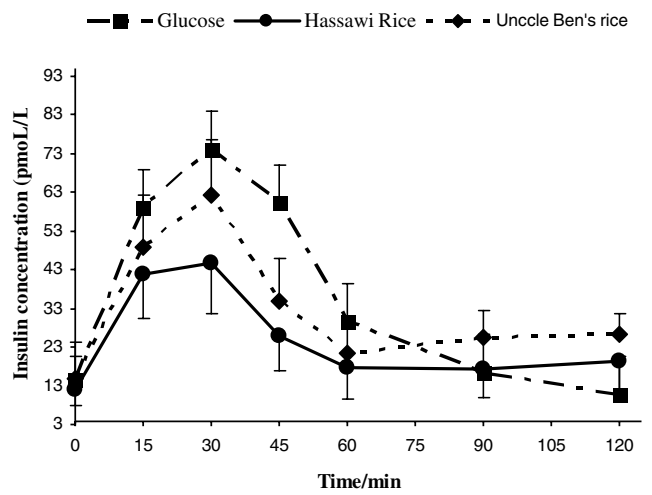

Fig. 2. Plasma insulin response during $2 \mathrm{~h}$ following reference glucose, Hassawi Rice and Uncle Ben's rice. Values are means with their standard errors represented by vertical bars.

1. Jenkins DJ, Wolever TM, Taylor RH et al. (1981) Am J Clin Nutr 34, 362-366.

2. Englyst KN, Hudson GJ \& Englyst HN (2000) In Encyclopaedia of Analytical Chemistry, pp. 4246-4262 [RA Meyers, editor]. Chichester, West Sussex: John Wiley \& Sons.

3. Food and Agriculture Organization/World Health Organization (1997) Carbohydrate and Food Nutrition. Report of a Joint FAO/WHO Expert Consultation. FAO Food and Nutrition Paper no. 66. Rome: FAO.

4. Association of Official Analytical Chemists (1995) Official Methods of Analysis, 16th ed. Washington, DC: AOAC. 